\title{
Enhance The Quality of Cellulosic Fibers Produced from Agricultural Wastes through Flocculation Using Chitosan
}

\author{
Samar H. Mohamed, Mona A. El-Sabour, Zenat A. Nagieb* \\ Cellulose and Paper Department, National Research Centre, Tahrir St., Dokki, \\ Cairo, P O 12622, Egypt.
}

\begin{abstract}
PAPER sheets were prepared by using different types of cellulosic fibers produced from agricultural wastes. Chitosan solutions with different concentrations were added to the surface of paper sheets. Mechanical properties enhanced in case of treated paper sheets with chitosan comparing with untreated. Generally, in all cases of paper sheets prepared from different pulps, the strength properties reached their optimum enhancement in presence of $0.5 \%$ chitosan solution almost. Physical properties enhanced by addition of chitosan. Paper sheets prepared from unbleached bagasse treated with chitosan gave the best results compared with that prepared from the others. Also, paper sheets prepared from unbleached rice straw and that prepared from unbleached mixed (rice straw and 25\% bagasse) gave impressive results. Crystallinity index from the ratio A $1435 \mathrm{~cm}-1 /$ A $900 \mathrm{~cm}-1$ in Infrared spectra proved all the above. It was observed from the morphology of fibers that fibers of the sized paper enhanced and became tight and smooth.
\end{abstract}

Keywords: Paper sheets, Chitosan, Physical properties, Mechanical properties.

\section{Introduction}

Rice straw and bagasse considered the most important agricultural residues that need attention because of the resulting pollution to the environment, so they are used in the paper industry to take advantage of them because they exist in abundance. They are very important for writing, printing or for packaging $[1,2]$. Sizing is used as an adhesive to paper to add enhanced properties. Sizing keeps the fibers from breakdown due to oxidation. Fillers caused weakening the sheet; sizing adds adhesive qualities and strength to paper [3]. Different types of polymers are very important sizes today for hand papermaking. They have high properties and they are inexpensive.

Surface sizing agents are used to bring paper sheets have several properties such as waterresistance and printability [4,5]. These agents are applied to fine paper, newspaper, ink-jet printing paper, liner board, and so on. Surface sizing produced a film-forming material to the surface of the sheet, subsequent to sheet formation. Starches are the most popular Surface sizing agents used in paper manufacture. Hydrophobic and hydrophilic ends are involved in sizing agents. The sizing agent adheres to substrate fibers and forms a film, with the hydrophilic tail facing the fiber and the hydrophobic tail facing outwards, resulting in a smooth finish that tends to be water-repellent.

Chitosan[6,7] is a linear polysaccharide has linear polyamine, reactive amino groups, reactive hydroxyl groups available, and chelates many transitional metal ions.

Biodegradable chitin[8,9] and chitosan can strengthen recycled paper and increase the environmental friendliness of packaging and other products. Chitosan is already involved in the manufacture of paper because chitosan molecules greatly resemble those of cellulose the main constituent of plant walls. Lastly the paper produced with chitosan has a smoother surface and is more resistant to moisture. Among other things, chitosan is of great value in the production of toilet paper and for wrapping paper and cardboard $[10,11]$.

The synthesis of chitosan is done commercially by deacetylation of chitin[12,13], which is the structural element in the exoskeleton of crustaceans (such as crabs and shrimp) and cell walls of fungi. A common method for the synthesis of chitosan [14-17] is the deacetylation of chitin using sodium hydroxide in excess as a reagent and water as a solvent. 


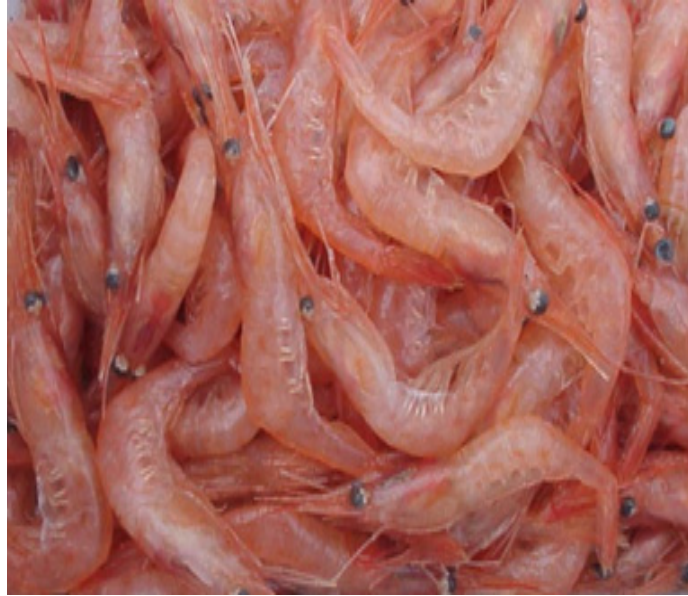

The chemical structures of cellulose and chitosan are given below [18- 20]

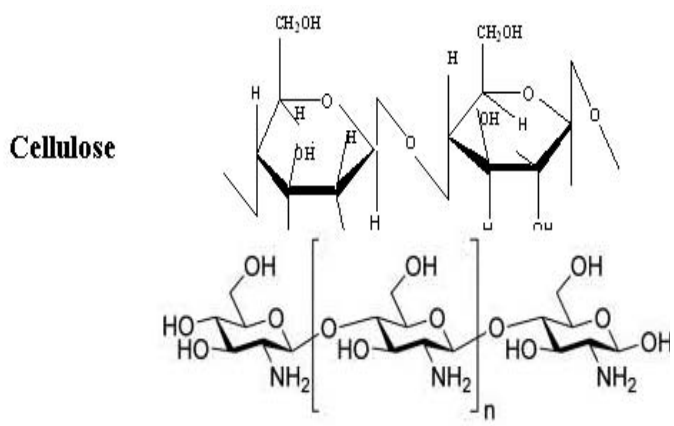

\section{Chitosan}

The aim of this work was investigating the use of chitosan solutions with different concentrations to enhance the mechanical and physical properties of paper sheets. Paper sheets used here were prepared from different pulps unbleached bagasse, unbleached rice straw and unbleached mixed pulps. Mechanical and Physical properties of paper sheets were studied. Infrared spectroscopy and scanning electron microscopy were also investigated.

\section{Experimental}

\section{Materials}

1. Unbleached bagasse, unbleached rice straw and unbleached mixed (rice straw and 25\%bagasse) pulps were used as a base furnish to prepare papers, supplied by Edfo Paper Mill, Upper Egypt.

2. Chitosan (highly molecular weight) was supplied by Sigma-Aldrich with $75-85 \%$ deacetylated. Different concentrations of Chitosan, $\%(w / v)$ in $1 \%$ acetic acid were prepared.

\section{Paper making}

The pulps were chemically analyzed for $\alpha$-Cellulose, pentosans, lignin, and ash, according to standard methods [21].

The paper sheets were prepared according to the method described in our previous reports [3].

\section{Calendaring process}

The sheets before and after adding polymer solutions on surface were subjected to calendaring process at $\left(100 \mathrm{KN}, 60^{\circ} \mathrm{C}, 3 \mathrm{~min}\right)$ using Hydraulic Press and then to the following tests.

\section{Mechanical properties}

Tensile index and burst strength had been measured. For each test, at least five measurements were carried out $[22,23]$.

\section{Physical Properties}

Opacity and brightness had been measured $[22,23]$. For each test, at least five measurements were carried out.

\section{Infrared spectra}

The Infrared spectra for treated and untreated prepared papers fiber were measured via Fourier Standardize Infrared spectrometer (FT/IR-6100, Jasco, Japan). All spectra were recorded in the range $(4000-400 \mathrm{~cm}-1)$, the scans number was 128. The resolution was $4 \mathrm{~cm}-1$ and scan speed 2 $\mathrm{mm} / \mathrm{s}$. Infrared spectra of the papers fiber were prepared in reflection \% to study the chemical composition.

\section{Scanning electron microscopy}

Scanning electron microscopy (SEM) was conducted on JEDL JEM-100 S electron microscope using the gold - Sputtering technique.

\section{Results and Discussion}

Table 1 shows chemical analysis of different pulps.

Table 1. Chemical analysis of different pulps.

\begin{tabular}{|c|c|c|c|c|}
\hline Type of pulp & $\begin{array}{c}\text { Liginin, } \\
\%\end{array}$ & $\begin{array}{c}\text { Pentosan, } \\
\%\end{array}$ & $\begin{array}{c}\text { Aphar-Cellubse, } \\
\%\end{array}$ & \begin{tabular}{|c|} 
Ash, \\
$\%$ \\
\end{tabular} \\
\hline Unbleachled bagasse & 5.4 & 25.6 & 69.0 & 09 \\
\hline $\begin{array}{c}\text { Unbleached nice straw } \\
\text { pupp }\end{array}$ & 5.6 & 23.9 & 68.4 & \\
\hline $\begin{array}{c}\text { Unbleached mived (fice } \\
\text { straw and 25\% bagasse) } \\
\text { pulp }\end{array}$ & 5.8 & 23.1 & 72.5 & 1.6 \\
\hline
\end{tabular}


Properties of treated paper sheets prepared from different pulps

From Fig. 1,2 and 3, it was clear that addition of chitosan solution enhanced mechanical properties (tensile index and burst strength)for paper sheets prepared from unbleached rice straw, unbleached bagasse and unbleached mixed (rice straw and $25 \%$ bagasse) pulps compared with untreated. The modification in the strength properties of paper sheets in presence of chitosan solution is due to the physical adsorption of chitosan solution on the surface and among the fibers, forming films around the fibers; these films enhanced binding of the fibers[24]. Therefore, the drying process of the paper sheets and calendaring process bonds the fibers together not only via hydrogen bonding among the fibers, but also through the formation of fiber-polymer-fiber bonds, but further increase in concentration of chitosan solution decreased these properties, this may be related to the high viscosity at higher polymer solution percentages, this prevented the penetration of the polymer through the fibers.

From Fig. 1, 2 and 3 it was obvious that addition of $0.5 \%$ chitosan solution gave the high results in mechanical properties (tensile index and burst strength) for paper sheets prepared from different pulps. Physical properties increased by increasing percentage of chitosan solution for paper sheets prepared from different pulps; this was related to physical properties of polymer [25].

Figures 1, 2 and 3 investigated that cellulosic fibers produced from agricultural waste improved through flocculation using chitosan. This clearly exists in the case of paper sheets prepared from unbleached rice straw pulp by comparing with untreated. It was supposed that fixation of the chitosan onto/or within the cellulose structure is accompanied by the formation of semi-interpenetrated network structure which results in providing best stiffness and pilling resistance [3]. Properties of treated paper sheets prepared from unbleached bagasse in presence of number of layers of $0.5 \%$ chitosan solution

Paper sheets prepared from unbleached bagasse treated with $0.5 \%$ chitosan solution has been chosen due to its presence in abundance as agricultural residues and also observed enhancement in the properties of the paper sheets by comparing with untreated.

Figure 4 investigated that mechanical properties of treated paper sheets prepared from unbleached bagasse in presence of number of layers of chitosan solution $0.5 \%$ increased by increasing number of layers. This confirms that the improvement in the strength properties of paper sheets in presence of chitosan solution is due to the physical adsorption of chitosan on the surface and among the fibers, forming films around the fibers; these films enhanced binding of the fibers [26]. Therefore, the drying process of the paper sheets and calendaring process bonds the fibers together not only via hydrogen bonds between the fibers, but also through the formation of fiber-polymer-fiber bonds and fixation of the chitosan onto/or within the cellulose structure is accompanied by the formation of semi-interpenetrated network structure which results in providing good stiffness and pilling resistance.

From Fig. 4, it was clear that opacity increased by increasing number of layers but brightness decreased by increasing number of layers
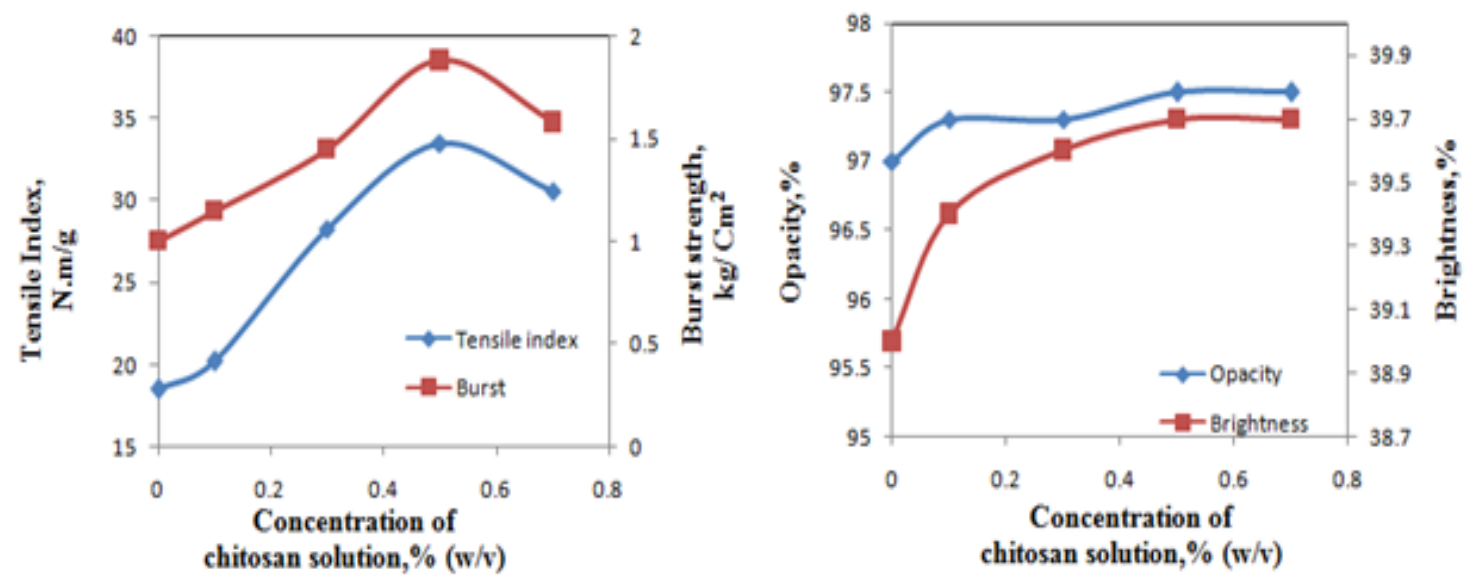

Fig. 1. Properties of treated paper sheets prepared from unbleached bagasse pulp. 

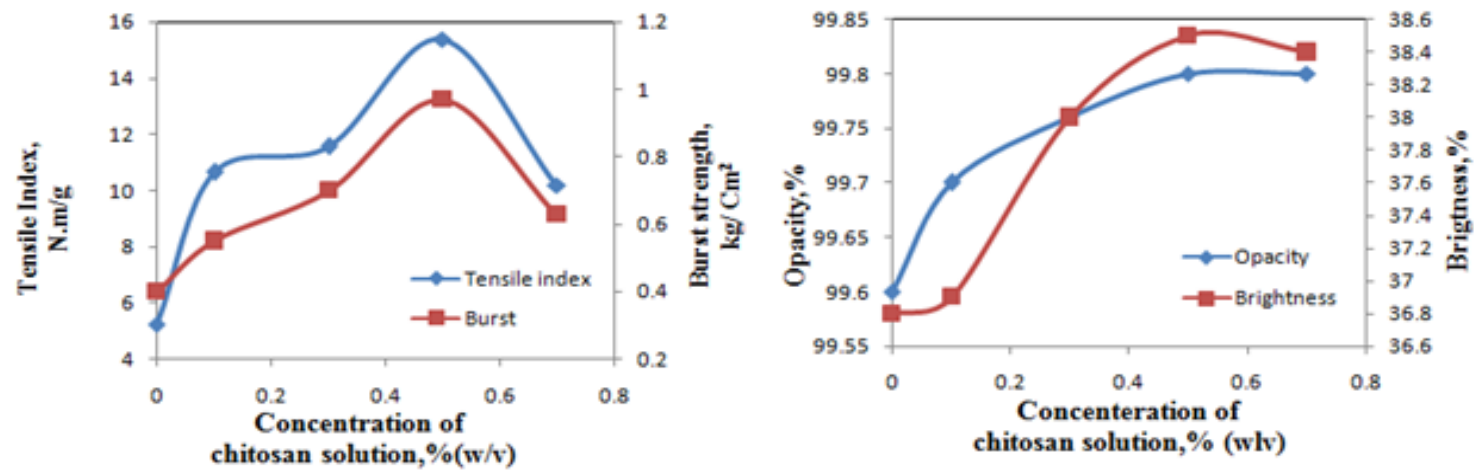

Fig . 2. Properties of treated paper sheets prepared from unbleached rice straw pulp .
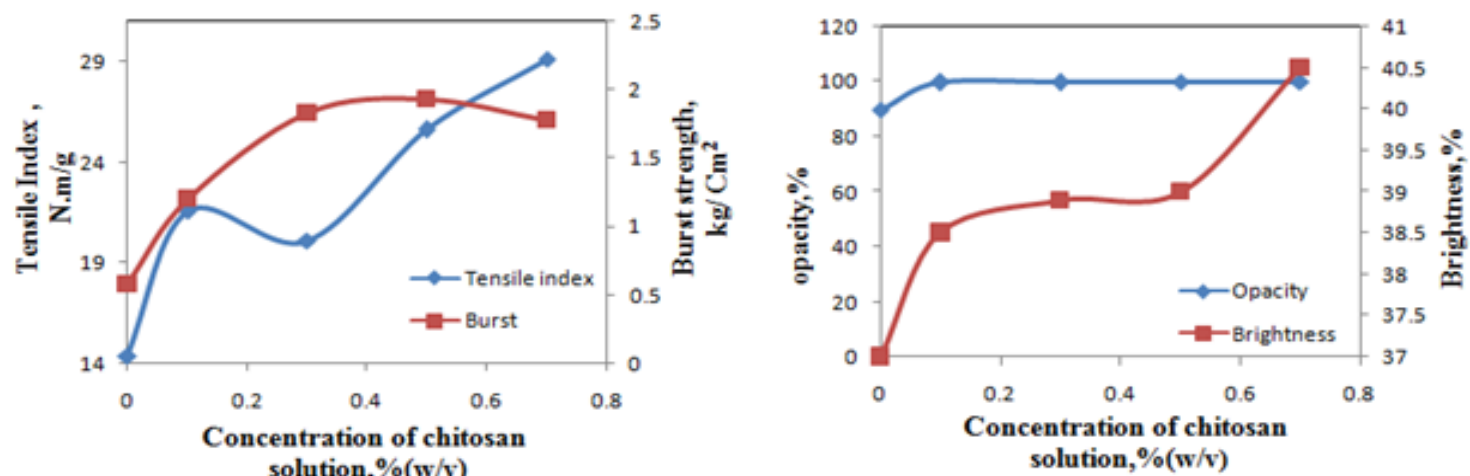

Fig. 3. Properties of treated paper sheets prepared from mixed unbleached (rice straw and $25 \%$ bagasse) pulp.
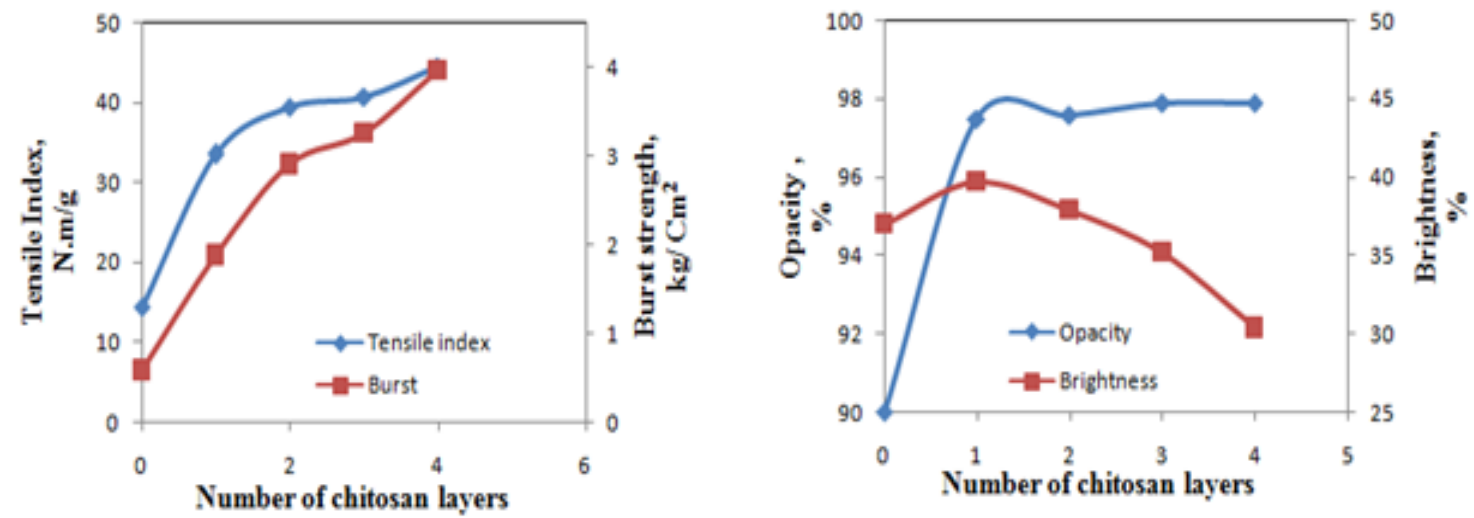

Fig. 4. Properties of treated paper sheets prepared from unbleached bagasse pulp at different chitosan layers.

Infrared spectra

Table 2 shows the ratio A $1435 \mathrm{~cm}-1 /$ A900 cm-1 which represents the crystallinity index for paper sheets prepared from different pulps. Crystallinity index increased in case of treated paper sheets prepared from unbleached rice straw, unbleached bagasse and unbleached mixed (rice straw and $25 \%$ bagasse) pulp compared with untreated, indicating that treated paper sheets contain more hydrogen bonds among the hydroxyl groups in cellulosic chain and polymers.

In Table 2 and Fig. 5,6 it was clear that Crystallinity index increased in case of treated paper sheets prepared from unbleached bagasse pulp treated with different numbers of layers of chitosan as the number of layers increased. 
TABLE 2. The ratio A1435 cm-1/ A $900 \mathrm{~cm}-1$ which represents the crystallinity indexes for paper sheets.

\begin{tabular}{|c|c|c|c|}
\hline $\begin{array}{c}\text { Type of pulp and } \\
\text { concentration of } \\
\text { polymer solution }\end{array}$ & $\begin{array}{c}\text { crystallinity } \\
\text { indexes }\end{array}$ & $\begin{array}{c}\text { Type of pulp and concentration } \\
\text { of polymer solution }\end{array}$ & $\begin{array}{c}\text { crystallinity } \\
\text { indexes }\end{array}$ \\
\hline $\begin{array}{c}\text { Paper made from } \\
\text { unbleached bagasse } \\
\text { pulp }\end{array}$ & 1.195 & $\begin{array}{c}\text { Paper made from unbleached } \\
\text { mixed (rice straw and } 25 \% \\
\text { bagasse) pulp treated with } 0.5 \% \\
\text { chitosan }\end{array}$ & 1.201 \\
\hline $\begin{array}{c}\text { Paper made from } \\
\text { unbleached rice } \\
\text { straw pulp }\end{array}$ & 0.983 & $\begin{array}{c}\text { Paper made from unbleached } \\
\text { bagasse pulp treated with one } \\
\text { layer from 0.5\% chitosan }\end{array}$ & 1.216 \\
\hline $\begin{array}{c}\text { Paper made from } \\
\text { unbleached mixed } \\
\text { (rice straw and } 25 \% \\
\text { bagasse) pulp }\end{array}$ & 1.098 & $\begin{array}{c}\text { Paper made from unbleached } \\
\text { bagasse pulp treated with two } \\
\text { layers from } 0.5 \% \text { chitosan }\end{array}$ & 1.291 \\
\hline $\begin{array}{c}\text { Paper made from } \\
\text { unbleached bagasse } \\
\text { pulp treated with } \\
0.5 \% \text { chitosan }\end{array}$ & 1.216 & $\begin{array}{c}\text { Paper made from unbleached } \\
\text { bagasse pulp treated with three } \\
\text { layers from } 0.5 \% \text { chitosan }\end{array}$ & 1.528 \\
\hline $\begin{array}{c}\text { Paper made from } \\
\text { unbleached rice } \\
\text { straw pulp treated } \\
\text { with } 0.5 \% \text { chitosan }\end{array}$ & 1.113 & $\begin{array}{c}\text { Paper made from unbleached } \\
\text { bagasse pulp treated with four } \\
\text { layers from } 0.5 \% \text { chitosan }\end{array}$ & 1.529 \\
\hline
\end{tabular}

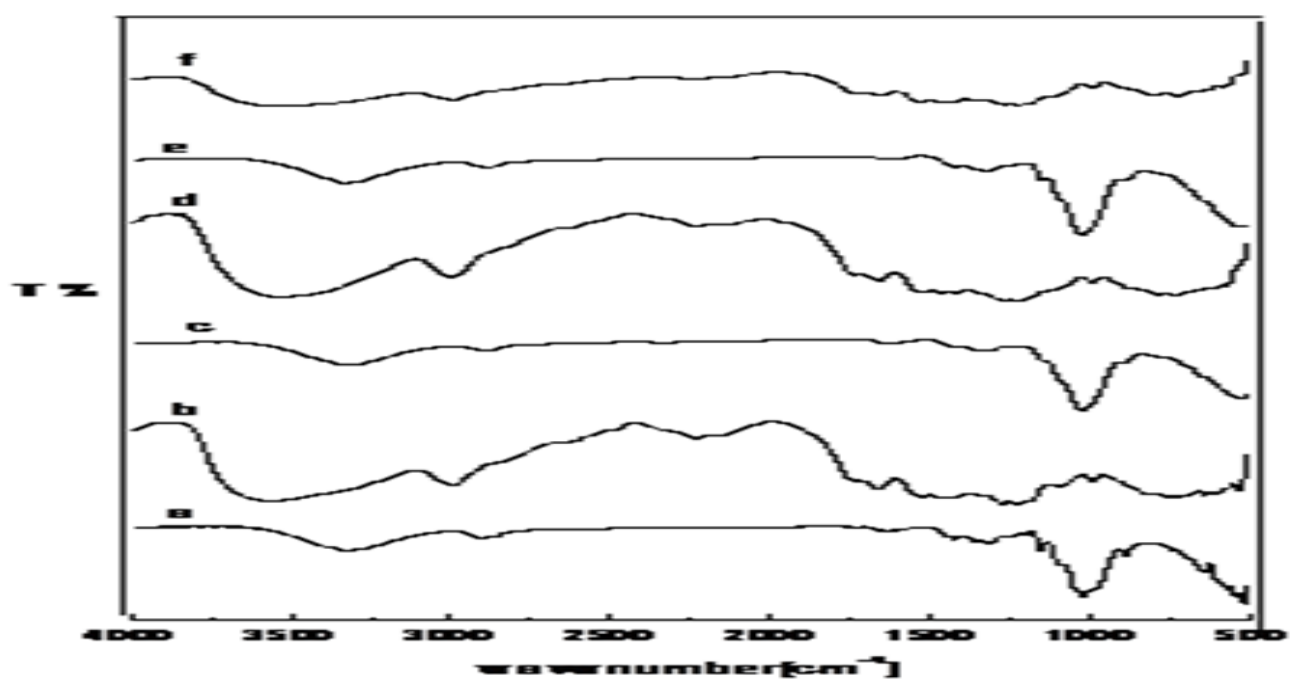

Fig. 5. FT-IR characterization for untreated paper sheets obtained from unbleached bagasse pulp(a), bagasse treated with $0.5 \%$ chitosan (b), untreated mixed pulp(c), treated mixed pulp (d), untreated rice straw (e), treated rice straw (f). 


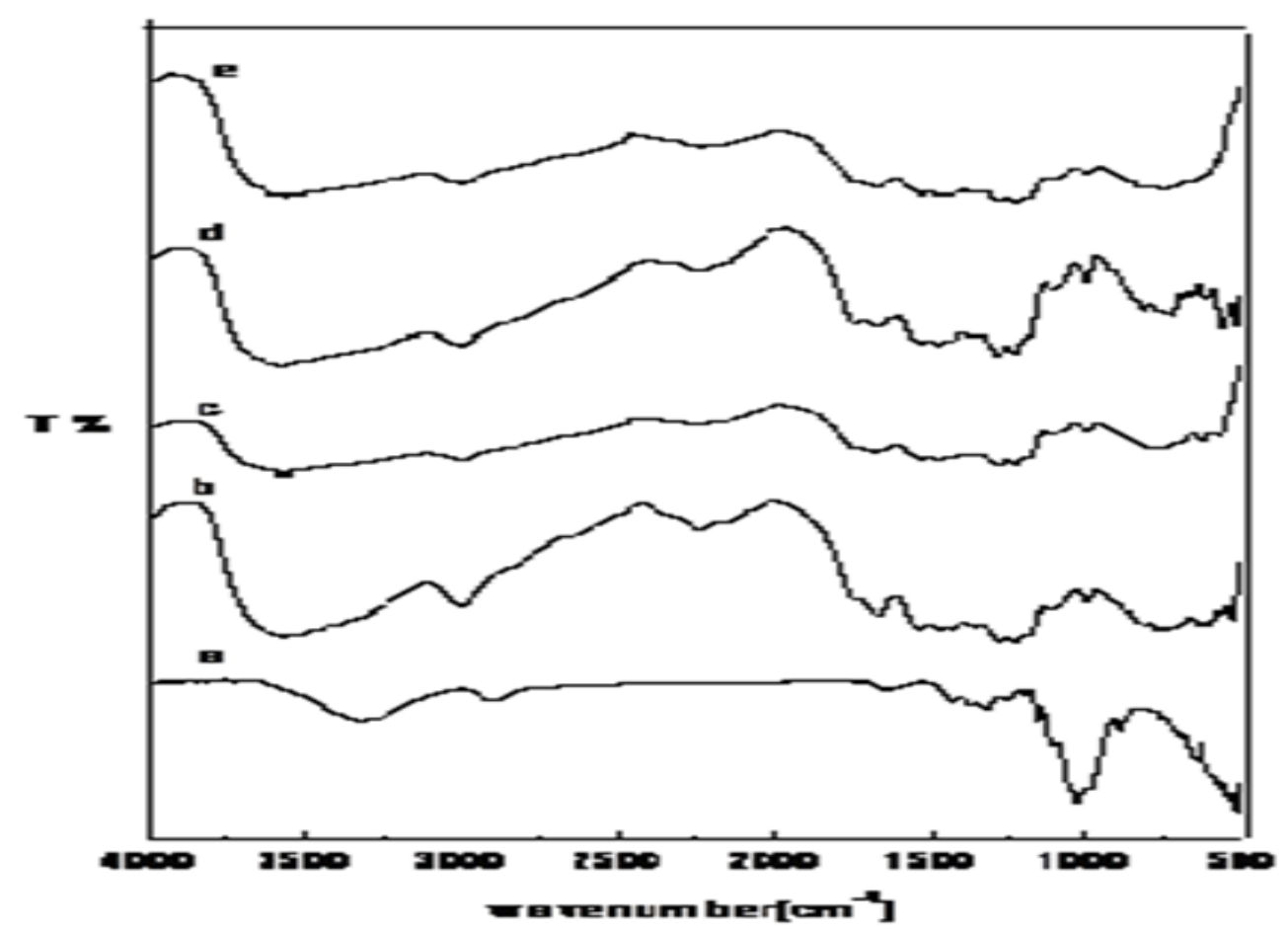

Fig. 6. FT-IR characterization for untreated paper sheets obtained from unbleached bagasse pulp(a), bagasse pulp treated with $0.5 \%$ chitosan, one layer(b), two layers(c), three layers(d), four layers (e).

\section{Scanning electron microscopy}

It was obvious from Photographs of Fig.7 comparing with that in Fig. 8 that paper sheets prepared from unbleached rice straw, unbleached bagasse, and unbleached mixed (rice straw and $25 \%$ bagasse) pulps treated with chitosan solution, presented certain adhesion among the fibers, and had more compact structure than untreated sheets, showing a clearer pulp with no fibrillation or filaments among the fibers, no cracks or voids, thus the crack does not have a straight path because it has to move around the fiber cells and ultimately stops[1].

Also from Fig. 7, 8, it was clear that the fibers of the sized paper were tight and smooth. These proved that the sizing emulsion permeated into

\section{(a)}

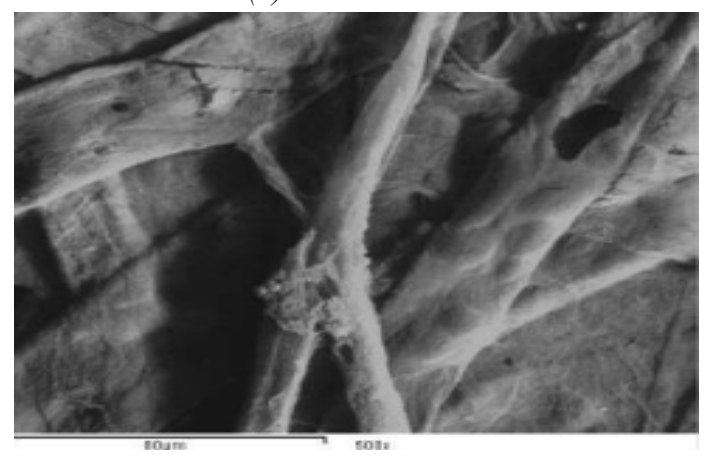

Egypt. J. Chem. 61, No. 1 (2018) the paper fibers and interacted with the paper fibers by physical and chemical effects, which strengthened the binding force and bond energy among the fibers, thus enhancing the physical strength of the paper. From the morphology of the fibers at the surface of the paper, it can be seen that surface of sized papers looks very smooth and glossy in the micrograph whereas the surface of unsized papers was rather crude and unpolished [27].

Figure 9 represented photographs of treated paper sheets prepared from unbleached bagasse pulp treated with different numbers of layers of $0.5 \%$ chitosan. From Fig. 9(a-d), it was obvious that as the number of layers increases, the sized paper became more tight.

(b)

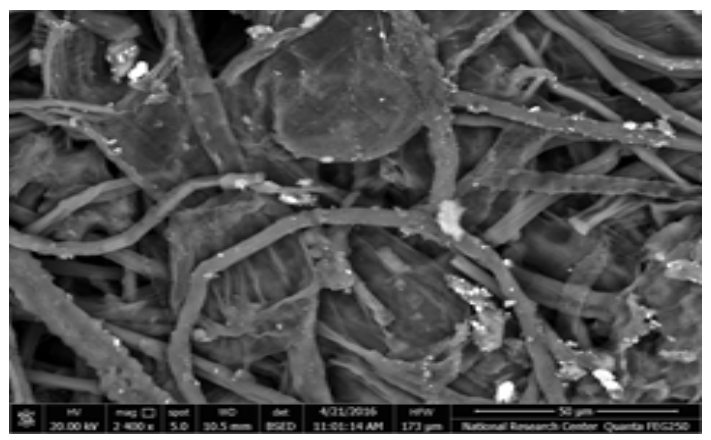




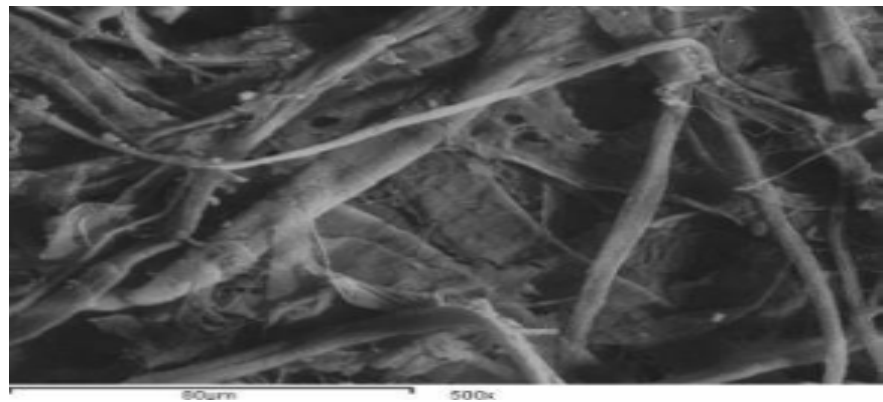

(c)

Fig. 7. Photographs of untreated paper sheets obtained from unbleached bagasse pulp(a), unbleached rice straw pulp(b), unbleached (rice straw and $25 \%$ bagasse) pulp(c).

(a)
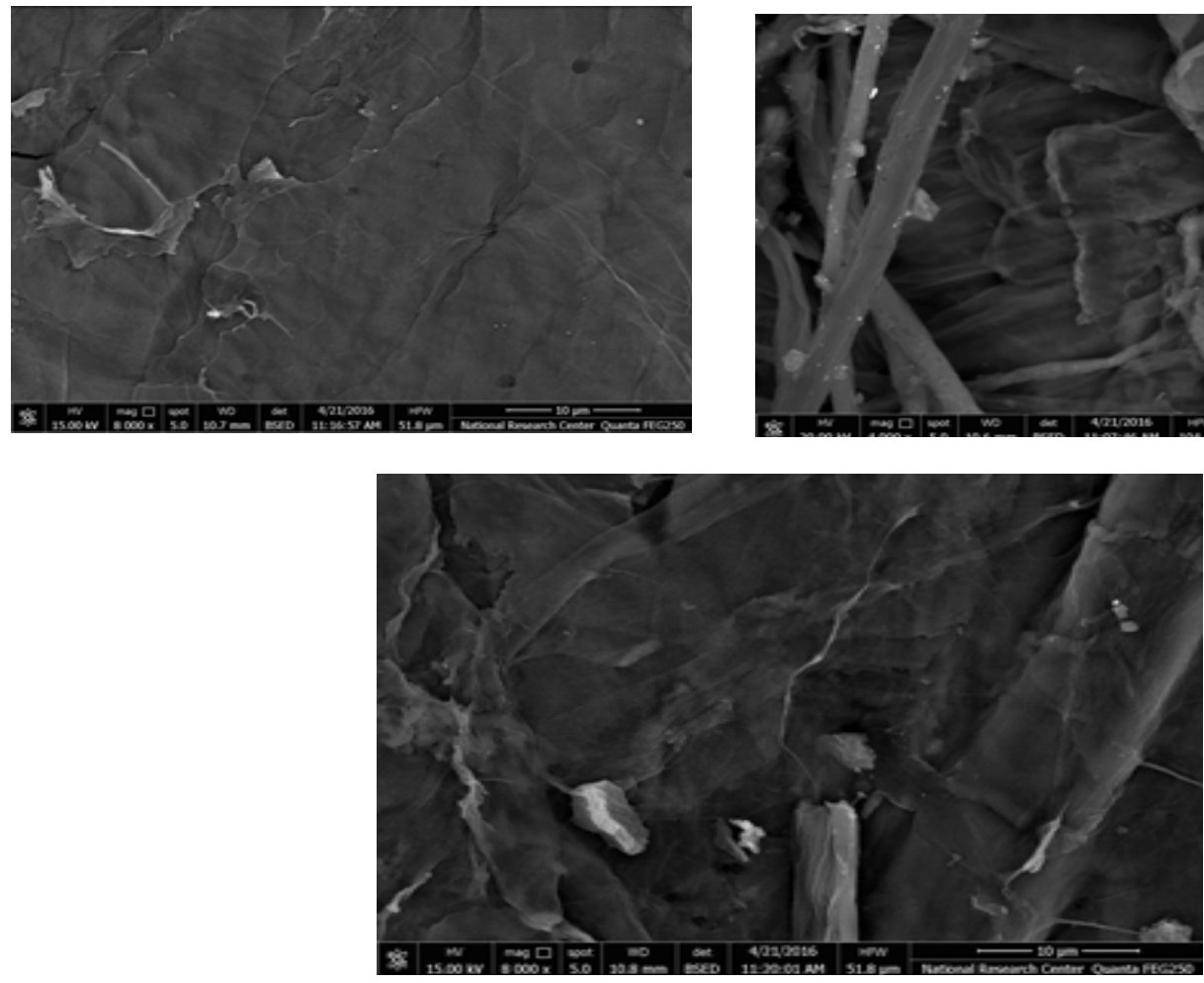

Fig. 8. Photographs of treated paper sheets obtained from unbleached bagasse pulp treated with $0.5 \%$ chitosan (a), treated rice straw pulp (b), treated mixed (rice straw and $25 \%$ bagasse) pulp (c).

(a)

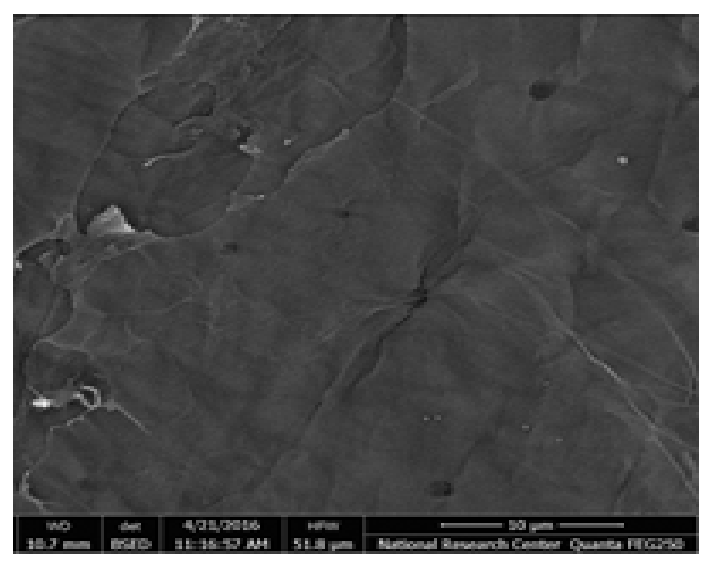

(b)

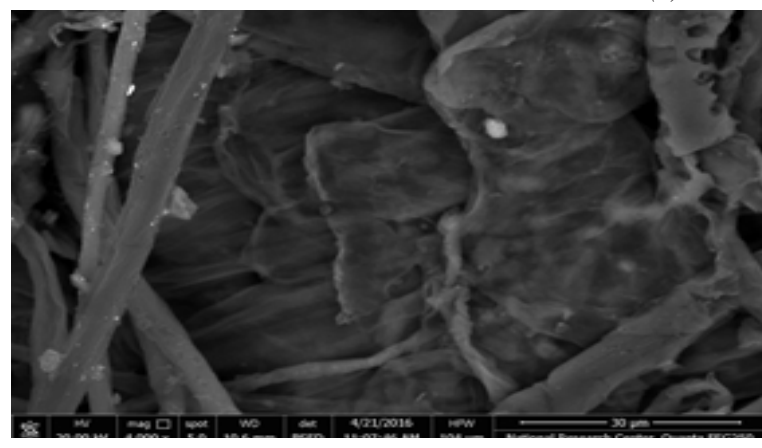

(c)

(b)

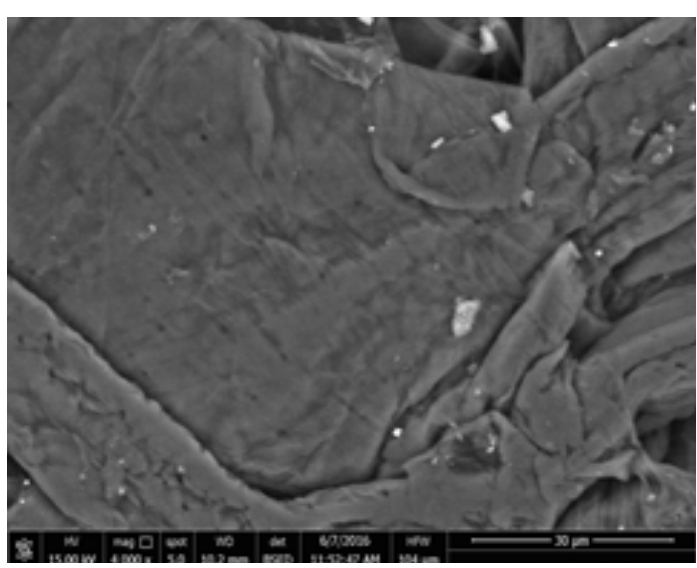

Egypt. J. Chem. 61, No.1 (2018) 
(c)

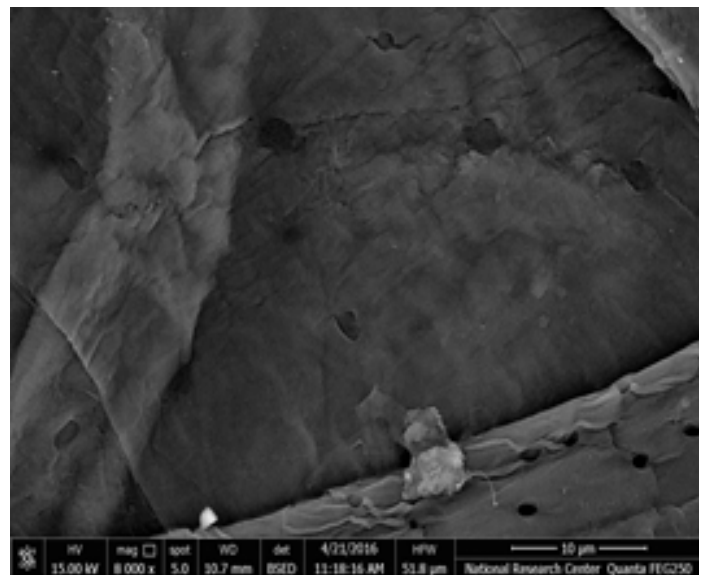

(d)

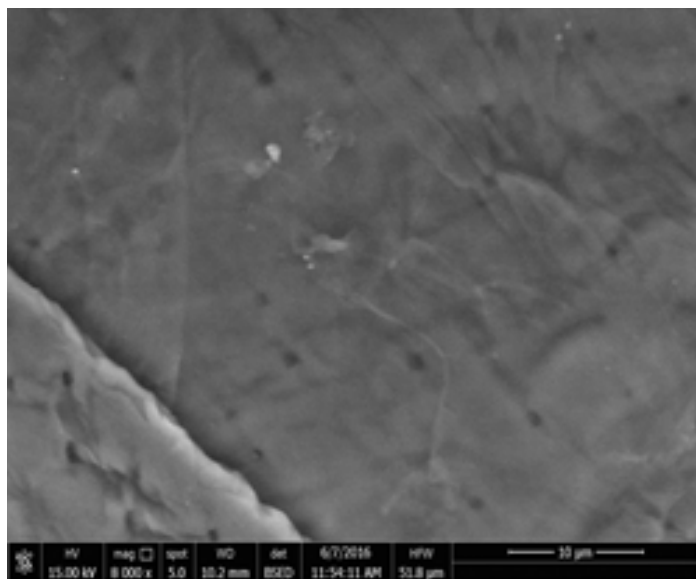

Fig. 9. Photographs of treated paper sheets obtained from unbleached bagasse pulp treated with $0.5 \%$ chitosan, (a) one layer, (b) two layers, (c) three layers, (d) four layers.

\section{Conclusion}

1. Addition of $0.5 \%$ chitosan solution gave the best results in mechanical properties (tensile index and burst strength) for paper sheets prepared from unbleached bagasse, unbleached rice straw and unbleached mixed (rice straw and 25\%bagasse) pulps compared with untreated.

Physical properties increased by increasing percentage of chitosan solution for all paper sheets prepared from different pulps.

2. Mechanical properties of treated paper sheets prepared from unbleached bagasse in presence of number of layers from $0.5 \%$ chitosan solution increased by increasing number of layers. Opacity increased by increasing number of layers but brightness decreased by increasing number of layers.

3. Crystallinity index from Infrared spectra increased in case of treated paper sheets prepared from, unbleached rice straw, unbleached bagasse and unbleached mixed(rice straw and $25 \%$ bagasse) pulps compared with untreated, also crystallinity index increased in case of treated paper sheets prepared from unbleached bagasse pulp treated with different numbers of layers of chitosan as the number of layers increased.

4. Scanning electron microscopy proved that the surface of sized papers looks very smooth and glossy in the micrograph, whereas the surface of unsized papers was rather crude and unpolished. Photographs of treated paper sheets prepared from unbleached bagasse pulp treated with different layers of $0.5 \%$ chitosan proved that as the numbers of layers increased, the sized paper became more tight.

\section{References}

1. Mohamed, S.H., Khafagi, M. G., Nagieb, Z A. and El-Samahy M. A., Investigation studies of microwave effect on structure of cellulosic Fibers (part I). International Journal of Advanced Research, 2, 129-138(2014).

2. Mohamed, S.H.,Nagieb, Z. A., Khafagi, M.G. and El-Sabour, M.A., Investigation studies of microwave effect on structure of cellulosic fibers II, International Journal of ChemTech Research, 9, 383-391( 2016).

3. Mohamed, S.H., Nagieb, Z.A. and El-Meligy, M.G., Enhanced physical, chemical and mechanical properties for different cellulosic fibers treated by different concentrations of polymers. International Journal of Advanced Research, 3, 880-893(2015).

4. Moutinho, I. M. T., Ferreira P.J. T. and Figureueiredo, F. M. L., Paper surface chemistry as a tool to improve inkjet printing quality, Bio Resources 6, 4259-4270(2011).

5. Xuechuan, W., Xiaoli, H., Longfang, R., Taotao, Q. and Sufeng, Z., Study of the preparation, characterization and sizing performance of modified collagen-surface sizing agent, Bio Resources 9, 1255-1266(2014).

6. Lee, D. W.et al., Strong adhesion and cohesion of chitosan in aqueous solutions, Langmuir, 29, 14222-14229(2013).

7. Shahidi, F. and Synowiecki, J., Isolation and characterization of nutrients and value-added products from snow crab (Chionoecetesopilio) and 
shrimp (Pandalus borealis) processing discards. Journal of Agricultural and Food Chemistry, 39, 1527-32(1991).

8. Lim C. and LeeD.W. et al. Contact time- and pHdependent adhesion and cohesion of low molecular weight chitosan coated surfaces. Carbohydrate Polymers, 117, 887-894(2015).

9. Hadwiger, L. A., Multiple effects of chitosan on plant systems: Solid science or hype. Plant Science 208, 42-9 (2013).

10. Habibie, S., Hamzah, M., Anggaravidya, M. and Kalembang, E., The effect of chitosan on physical and mechanical properties of paper, Journal of Chemical Engineering and Materials Science, 7, 1-10, (2016).

11. Kean, T., Roth, S. and Thanou, M.,Trimethylatedchitosans as non-viral gene delivery vectors: Cytotoxicity and transfection efficiency. Journal of Controlled Release 103, 643-53(2005).

12. Struszczyk, M.H., Applications of chitosan, Polymery 47, 396-340 (2002).

13. Pitaloka, A.B., Saputra, A.H. and Nasikin, M., Water hyacinth for superabsorbent polymer material, World Appl. Sci. J., 22,747754(2013).

14. Reis, A.B., Yoshida, C.M.P., Vilela, E.S.D., Nascimento, R.D., MeloI.S. and Franco,T.T., Biodegradability kraft paper coated with films emulsified chitosan and palmitic acid, J. Res. Updates Polym. Sci.,2, 122-131(2013).

15. Kuusipalo, J, Kaunisto, M., Laine, A. and Kellomäki, M., Chitosan as a coating additive in paper and paperboard, TAPPI J, 4, 17-21(2005).

16. Miranda, R., Nicu, R., Latour, I., Lupei, M., Bobu, E. and Blanco, A. Efficiency of chitosans for the treatment of papermaking process water by dissolved air flotation, Chem. Eng. J.,231, 304313 (2013).

17. Gavhane, Y.N., Gurav, A.S. and Yadav,A.V.Chitosan and its applications: A Review of Literature, Int. J. Res. Pharm. Biomed. Sci.,4, 312-331(2013).
18. Linda, T., Muthupoongodi S., SahayaShajan,X. and Balakumar S., Effect Of Chitosan On Photocatalytic Degradation Of Congo Red Dye Using PVC/TiO2Nano Composites Under UV-Light Irradiation, International Journal of ChemTech Research, 6, 5378-5381 (2014).

19. Shanthi, P. and Kothai, S., Synthesis and characterization of chitosan with incorporated herb - A novel bionano composite. International Journal of ChemTech Research, 8, 208-214 (2015).

20. Ahamed, M.I.N., Sastry, T.P. and Kashif, P.M.,Antibacterial activity of cellulose-chitosan composite incorporated with silver nanoparticles, International Journal of PharmTech Research, 3, 1303-1304( 2011).

21. Casey, J. P., Paper Testing And Converting In Pulp And Paper (3rd ed.). New Yourk Interscience Publisher, 1714-1965(1981).

22. Method No.411. The Institute of Paper Chemistry, Appleton (Wis)(1952).

23. Method D 1925-70. American Society for Testing and Materials (ASTM) (1965).

24. Laura,v., Marianna,L., Inese, S., Linda, R., Uldis, G., Juris, Z., Raphael, P., Effect of chitosan on the properties of fiber for packing. Cellulose Chem. Technol., 51 (1-2), 67-73(2017).

25. Somwang K., Chutatip K.,and Sumaida S., Effects of shrimp chitosan on the physical properties of hand sheets.Agriculture and Natural Resources 1-4 (2017).

26. Alireza A., Warwick D. Raverty. Effect of Chitosan Addition on the Surface Properties of Kenaf (Hibiscus cannabinus) Paper. Fibers and Polymers 6 (2), 174-179(2005).

27. Guo, Y. H., Guo, J. J., Li, S. C., Li, X., Wang, G. S. and Huang, Z., Properties and Paper Sizing Application of Waterborne Polyurethane emulsions synthesized with TDI and IPDI, Colloids and Surfaces A: Physicochem. Eng. Aspects.,427, 53-61(2013).

(Received 15/11/2017; Accepted 19/12/2017) 


\section{تعزيز جودة الألياف السليلوزية المنتجة من المخلفات الزراعية من خلال التلبد باستخدام الكيتوزان

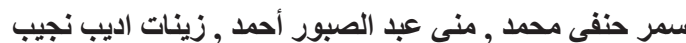

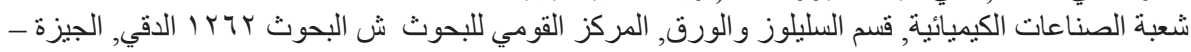

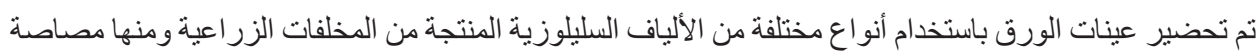

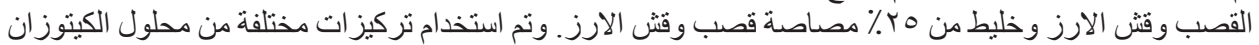

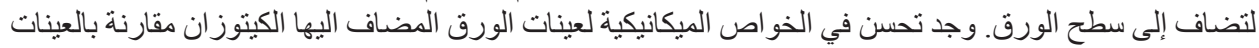

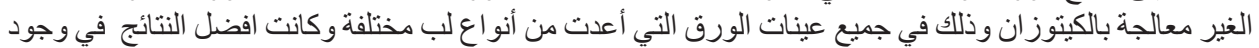

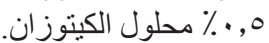

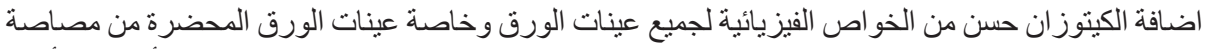

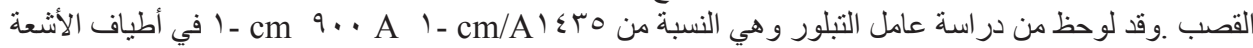
تحت الحمر اء تحسن في شكل الا لياف التي اصبحت درل محكمة وناعمة. 